\title{
Anti-Competitive CONDUCT, IN-House R\&D, AND GROWTH
}

\author{
VOLKER GROSSMANN \\ THOMAS M. STEGER
}

\author{
CESIFO WORKING PAPER NO. 1963 \\ CATEGORY 5: Fiscal Policy, MaCROECONOMICS AND GROWTH \\ APRIL 2007
}

An electronic version of the paper may be downloaded

- from the SSRN website:

- from the RePEc website:

wWw.SSRN.com

- from the CESifo website:

www.RePEc.org

www.CESifo-group.de 


\title{
ANTI-COMPETITIVE CONDUCT, IN-HOUSE R\&D, AND GROWTH
}

\begin{abstract}
Incumbent firms have two basic possibilities to improve their competitive position in the product market: investment in R\&D and the creation of entry barriers to the disadvantage of potential rivals, e.g. through lobbying activities, campaign contributions, bribes or the adoption of incompatible technologies. This paper proposes a simple oligopoly model which raises the possibility that such anti-competitive conduct and $\mathrm{R} \& \mathrm{D}$ investment are complementary activities for incumbents. Consequently, an institutional framework or technological possibilities which encourage anti-competitive conduct, although impeding entry of potential rivals and accentuating standard oligopoly distortions, may foster R\&Dbased growth and welfare. However, this outcome is less likely if entrants exert technological spillover effects, e.g. through foreign direct investment. Stronger protection of intellectual property rights, although triggering anti-competitive conduct and thereby impeding market entry as well, is more likely to foster economic growth.
\end{abstract}

JEL Code: L13, O31, O40.

Keywords: anti-competitive conduct, in-house R\&D, economic growth, entry barriers, knowledge spillovers.

\author{
Volker Grossmann \\ Department of Economics \\ University of Fribourg \\ Bd. de Pérolles 90 \\ 1700 Fribourg \\ Switzerland \\ volker.grossmann@unifr.ch
}

\author{
Thomas M. Steger \\ CER - Center for Economic Research \\ ETH Zurich \\ ZUE F 13 \\ 8092 Zurich \\ Switzerland \\ tsteger@ethz.ch
}

March 19, 2007

We are grateful to two anonymous referees and an associate editor for valuable and detailed comments. We are also indebted to Philippe Aghion, Josef Falkinger, Aderonke Osikominu, Peter Neary, Sjak Smulders, and seminar participants at Tilburg University, the Annual Meeting of the European Economic Association (EEA) in Vienna, the Annual Meeting of German Economists (Verein für Socialpolitik) in Bayreuth, and the Annual Meeting of the European International Business Association (EIBA) in Fribourg for helpful suggestions. 
"[R] egulation is acquired by the industry and is designed and operated primarily for its benefit." (Stigler, 1971)

\section{Introduction}

In a world of imperfect product market competition, incumbent firms have two basic possibilities to improve their competitive position in the product market: investment in $\mathrm{R} \& \mathrm{D}$ and the creation of entry barriers to the disadvantage of potential rivals (anticompetitive conduct). ${ }^{1}$ Evidence provided by Djankov et al. (2002) suggests that entry barriers can be understood by public choice theory of entry regulations (e.g. Stigler, 1971), stressing (i) lobbying activities of industry incumbents aiming at regulations which enhance their profits and (ii) politicians and bureaucrats who use regulations both to create rents for incumbents and to extract them through campaign contributions, votes and bribes. Resulting entry barriers may come, for instance, in the form of administrative burdens associated with registration of a business, legal barriers to entry which regulate the number of competitors allowed in a market through national, state or provincial laws, poorly communicated and non-transparent rules and procedural requirements for penetrating a market, and discrimination against foreign firms with respect to accessibility of information and appeal procedures. ${ }^{2}$ Besides affecting legislative entry regulations, incumbent firms may also contribute to technological barriers to entry. For instance, particularly in innovative and technologically advanced industries, incumbents often seek to adopt incompatible technologies (e.g. Salop and Scheffman, 1983; Krattenmaker and Salop, 1986).

This paper provides a first attempt to jointly analyze the decisions of incumbents to invest in $\mathrm{R} \& \mathrm{D}$ and to impede competition by raising rivals' entry costs. In a first step we analyze a simple static oligopoly model which suggests that investing in entry barriers

\footnotetext{
${ }^{1}$ A further possibility is advertising, which we do not consider in this paper. See Grossmann (2007) for a first attempt to analyze the interaction between $R \& D$ investments and advertising outlays of firms under free entry in monopolistically competitive markets, and its implications for economic growth and welfare.

${ }^{2} \mathrm{~A}$ rich set of measures of entry regulations in OECD countries is provided by Conway, Janod and Nicoletti (2005).
} 
and in $\mathrm{R} \& \mathrm{D}$ are complementary activities for incumbents. For instance, somewhat surprisingly, higher incentives of firms to raise rival's entry costs, possibly induced by the legal treatment of anti-competitive conduct in an economy or technological possibilities, may be conducive to R\&D effort of incumbents.

To examine the implications of this finding for economic growth and welfare, we extend the basic model to an endogenous growth framework with multiple industries and oligopolistic competition within an industry. Each industry consists of one incumbent and many potential entrants. We argue that whether the increased R\&D expenditure of incumbents, when fostered by a higher incentive for incumbents to impede entry, also implies faster growth or even higher welfare depends on the contribution of entrants to the economy's knowledge stock which can be accessed by innovating firms in the future. For instance, the literature on the impact of foreign direct investment sometimes suggests that foreign multinationals exert significant positive knowledge spillovers on the domestic economy. ${ }^{3}$ In this case, an environment which encourages anti-competitive conduct of incumbents may, by retarding entry, reduce both the economy's growth rate and welfare, though fostering R\&D investments of incumbents. However, if spillover effects are negligible, growth and welfare may increase, despite the fact that impeded entry triggered by higher anti-competitive effort of incumbents accentuate static oligopoly distortions. We also find that stronger protection of intellectual property rights (IPR) raises entry barriers by encouraging anti-competitive behavior of incumbents. In contrast to weaker regulations on anti-competitive conduct, however, growth effects are likely to be positive.

Our paper is related to several strands of literature. First, it builds on ideas from the literature on anti-competitive conduct, which has shaped our understanding of the profitability of incumbents' means to raise rivals' cost and their implications for output and prices (Salop and Scheffman, 1983, 1987). In their seminal contribution, Salop and Scheffman (1983) point out that, from the perspective of the predatory firm,

\footnotetext{
${ }^{3}$ Generally, however, the evidence is mixed. Positive FDI spillover effects seem to be confined to developed countries like the U.S. and to R\&D-intensive industries. The size of the effects varies considerably between studies. For discussions of the available evidence, see e.g. Keller (2004; section 6.2) and Egger et al. (2006).
} 
these strategies have some important advantages compared to predatory pricing: (i) they are credible, (ii) it is not necessary to sacrifice profits in the short run, and (iii) there is no need for superior access to financial resources. Gilbert (1989) provides an excellent overview on the literature on raising rival's costs as a profit-maximizing strategy of incumbents. However, this literature does not consider R\&D incentives or growth.

Secondly, our paper is related to an important recent literature which investigates the relationship between the intensity of product market competition and R\&D-based growth. For instance, van de Klundert and Smulders (1997) compare R\&D incentives of firms under Cournot and Bertrand competition in a growth model with in-house R\&D and show that growth is faster under Bertrand competition. Most closely related to our paper, Aghion et al. (2006) examine the effects of entry on incumbents' R\&D investment conditional on the distance of a sector to the world's technological frontier. Due to Bertrand competition and homogenous goods within an industry, profits of an incumbent firm are positive only if it is more productive than rivals and thus holds a monopoly. Hence, more distant to the frontier, a higher probability that an incumbent is replaced by a more productive entrant (i.e., a higher "entry threat") reduces the incumbent's R\&D incentives. To the contrary, if the incumbent possesses the frontier technology, it can deter entry by innovating. Thus, a higher entry threat encourages R\&D. The basic result suggested by the analysis, that higher entry encourages innovation incentives by incumbent firms in sectors that ex ante are close to the technological frontier and discourages $R \& D$ investments in sectors more distant to the frontier, is supported by firm level panel data for the UK. Consistent with this evidence, our model shows that if the number of entrants rises for exogenous reasons, incumbents which have sufficiently superior technology compared to entrants (being more likely if incumbents are close to the world's technology frontier) raise their R\&D investments. Techologically inferior incumbents, by contrast, adjust R\&D investment downward in response to increased entry. Our main contribution, however, is to investigate the relationship between incumbents' $\mathrm{R} \& \mathrm{D}$ and the number of rivals when we allow entry 
barriers, and therefore entry, to be endogenous in the sense that they are based on profit-maximizing investments of incumbent firms in anti-competitive conduct. The second key difference to our paper is that in Aghion et al. (2006) incumbent technology leaders can fully escape entry by innovating, whereas in our model incumbents respond to actual entry rather than to an entry threat and can only mitigate entry. ${ }^{4}$

Thirdly, Krusell and Rios-Rull (1996) propose a theory in which incumbent innovators have the possibility to block the emergence of superior technologies, i.e., vested interests of incumbents become an obstacle to development. Acemoglu et al. (2006) briefly discuss incentives of capitalists to buy support of politicians to restrict competition, which may give rise to an underdevelopment trap in the sense that the economy retains low-skill, non-innovating entrepreneurs. None of these papers, however, addresses our question whether the possibility of raising rivals' entry cost crowd out or complement R\&D spending of incumbents which do have the capability to innovate.

The remainder of this paper is structured as follows. In the next section we further motivate our analysis by turning to some anecdotal evidence on recent anti-competitive measures and entry barriers in innovative industries. Section 3 develops and analyzes a simple static oligopoly model. Section 4 extends the basic model to an endogenous growth framework, derives analytically comparative-static results on R\&D, anti-competitive conduct and growth, and numerically investigates welfare effects. In Section 5 we briefly discuss the link of the regulatory environment in South Korea to its macroeconomic development and argue that our model is consistent with this link. Section 6 concludes.

\footnotetext{
${ }^{4}$ In another interesting study, Aghion et al. (2005) theoretically and empirically find an inverted U-shaped relationship between product market competition and growth. In their theoretical model, the degree of price competition is inversely measured by the degree two technologically similar (neckand-neck) firms are able to collude. By assumption, there are at most two firms. A technologically leading firm owns a monopoly. It does not invest in $R \& D$, because in case the technologically lagging firm innovates it catches up with the leader and there is neck-and-neck competition. A higher degree of competition in an industry reduces post-innovation profits of the previously lagging firm (as well as profits of the previously advanced firm) and thereby discourages its R\&D. By contrast, in a neckand-neck industry, as firms can escape competition by innovating, higher competition raises R\&D investments by reducing pre-innovation profits. The analysis is not directly comparable to ours, however, as there is no entry in the model and incumbents can fully escape competition.
} 


\section{Anecdotal Evidence for Innovative Industries}

This section provides anecdotal evidence for anti-competitive activities of incumbents, and possibly resulting entry barriers, by considering some examples from R\&D-intensive industries. There is clear evidence indicating that anti-competitive activities may be of major importance. For instance, (reported) expenditures on lobbying targeted to the federal government of the United States amounted to $\$ 1.44$ billion in 1999 , according to the Center for Responsive Politics (www.opensecrets.org). Here we focus on highly innovative firms in the pharmaceutical, computer and electronic industry which may also be actively engaged in anti-competitive conduct.

The pharmaceutical industry in Switzerland is known as being, first, highly concentrated and, second, comparably R\&D intensive. Moreover, like the pharmaceutical sector in many other developed economies, the Swiss pharmaceutical sector is highly regulated. A comprehensive report, commissioned by the central government, on the consequences of public regulations for the price level of pharmaceutical products lists a large number of specific regulations (Infras / Basys, 2003, p. 59). Despite the fact that there may be good economic reasons for these regulations (i.e. a multiplicity of market failures), the report concedes that most regulations impede competition. Among these are patent protection, prohibition of parallel imports, and complicated and intransparent procedures for the admission of new pharmaceuticals. It is furthermore suspected that incumbent firms erect market entry barriers by impacting on the admission of pharmaceuticals. This is made possible, in principle, by the fact that the authority responsible for the admission of new pharmaceuticals (Swissmedic) is connected along several dimensions to the large incumbent firms. The most obvious interconnection lies in the fact that this authority is financed by the contributions of the incumbent firms (Infras / Basys, 2003, p. 166). To restrict the institutionalized possibility of large incumbents to hinder entry of other (possibly foreign) firms by rendering admission of new pharmaceuticals more difficult, the authors of the study therefore demand that the authority should be tax financed.

Another widely-discussed instance of anti-competitive conduct were the apparent 
attempts of Microsoft to secure its quasi-monopoly on operating systems by means which in 1998 the United States District Court for Columbia eventually deemed as violating competition law. In its final judgement, dated May 18, 1998, the court states: "Microsoft shall not retaliate against or threaten retaliation against an OEM [...] because it is known to Microsoft that the OEM is or is contemplating: 1. developing, distributing promoting, using, selling, or licensing any software that competes with Microsoft Platform Software or any product or service that distributes or promotes any Microsoft Middleware; 2. shipping a Personal Computer that (a) includes both a Windows Operating System Product and a non-Microsoft Operating System, or (b) will boot with more than one Operating System". Consistent with this judgement on "prohibited conduct", Fisher and Rubinfeld (2001) forcefully argue that Microsoft tied its Internet Explorer to Windows (giving it away for free) and imposed agreements on original equipment manufacturers (OEMs) to boycott other browsers not primarily to prevail in the browser market but because "Microsoft foresaw the possibility that the dominant position of Windows operating system would be eroded by Internet browsers and by cross-platform Java, both of which are capable of supporting platform applications that are operating system independent" (p. 3).

Consider finally a prominent example from the electronic industry. Apple is well known for being very successful in marketing its MP3 player iPod. To support sales of iPods, Apple has established the internet-based music store iTunes providing audiophiles. Importantly, these audiophiles can only be played with iPod and not with any MP3 player supplied by Apple's rivals. It is obvious that this business model uses a technological incompatibility to induce switching costs for Apple's customers. The potential disadvantages for customers and the competition impeding aspect of this strategy has led, on June 30th, 2006, France's Senate and National Assembly to pass a law which is supposed to allow customers to play music bought from iTunes on one of iPods' rivals (The Economist, 2006). The important aspect in the context of the present paper is that this strategy implements market entry barriers for potential rivals since any entrant must at first heavily invest in, say, advertisement to success- 
fully attract consumers. This example points once more to the conjecture that highly innovative firms with the capabilities to erect market entry barriers might, at the same time, be highly innovative. The question arising from this example which motivates our analysis reads: May Apple's technological opportunity to engage in anti-competitive conduct also spur its innovative activities?

\section{Basic Model}

\subsection{Set Up}

Consider the following linear demand model with vertical differentiation of goods and Cournot competition among oligopolistic, single-product firms. For simplicity, there is no horizontal differentiation of products. The inverse demand function for any variety $k \in\{1,2, \ldots, N\}$ takes the familiar form

$$
p_{k}=q_{k}-\gamma X, \text { with } X=\sum_{j=1}^{N} x_{j}
$$

where $\gamma>0, p_{k}$ and $q_{k}$ denote price and quality of good/firm $k$, respectively, $x_{j}$ gives the amount supplied by firm $j$, and $N$ is the number of products and firms in the considered industry. There are two types of firms: one incumbent and $m$ entrants. Thus, $N=1+m$. The number of entrants is endogenously determined. For simplicity, marginal production costs of all firms are set to zero.

The incumbent firm can incur in-house R\&D investments which determine product quality. These outlays constitute endogenous sunk costs at the product market competition stage (following Sutton, 1998, among others). Formally, we have

$$
q_{k}=\left\{\begin{aligned}
g(l) & \text { if } k \text { is incumbent } \\
\lambda & \text { if } k \text { is entrant }
\end{aligned}\right.
$$

where $l$ is R\&D cost incurred by the incumbent and $g(\cdot)$ is an increasing and strictly concave function. In the appendix it is shown that the quality of entrants, $\lambda>0$, has 
to be low enough for the incumbent to be viable in the competition with entrants and large enough for entering firms to be viable in the competition with the incumbent. $\lambda$ may be interpreted as inversely measuring the strength of intellectual property rights protection (IPR) in the considered economy: If IPR protection is strong, then imitation is retarded, which may be reflected by a low $\lambda$. More generally, we allow for $\lambda<g(l)$, which captures, for instance, that domestic entrants usually face lower market demand than incumbents. ${ }^{5}$ But we also allow for the case that the quality level of entrants exceeds the quality of incumbents, $\lambda>g(l)$, which captures the possibility that entering firms are technologically advanced multinationals from abroad.

There is free market access of entrants in the sense that firms enter as long as profits are non-negative, with a large number of potential entrants. However, these firms have to incur entry costs, which consist of two components. First, there may exist conventional (i.e. exogenous) sunk costs $f \geq 0$. In addition, entrants may have to incur cost which can be affected by the incumbent through "investment" in anticompetitive conduct, denoted by $b$. For instance, $b$ may be expenditure for lobbying, bribing politicians or adopting incompatible technologies. Resulting entry barriers may come in the form of red tape and barriers to foreign direct investment. Allowing incumbent firms to increase their potential rivals' sunk cost by such investments enables us to address the important question whether two of the most fundamental activities of firms to improve their competitive position in the product market, investment in $\mathrm{R} \& \mathrm{D}$ on the one hand and discouraging entry of rivals by anti-competitive conduct on the other hand, are complements or substitutes for incumbents.

Formally, suppose that entry costs of the incumbent's potential rivals are given by

$$
F(b ; \chi)=f+\chi h(b)
$$

where $h(\cdot)$ is an increasing and strictly concave function with $h(0)=0$ and $\chi>0$ captures the 'productivity' of anti-competitive conduct. As one possible interpretation,

\footnotetext{
${ }^{5}$ For an excellent review of the literature on firm entry and market shares of entrants, see Caves (1998).
} 
$\chi$ captures (inversely) the institutional quality of the economy's political and regulatory system. For instance, a high $\chi$ may indicate that lobbying activity is effective in protecting incumbents from competition through entry. A high $\chi$ may also capture technological conditions which are well-suited for the adoption of incompatible technologies. Comparative-static analysis with respect to both changes in $\chi$ and in the quality of rivals $\lambda$ (possibly affected by IPR) will play a key role for gaining insights in the nature of the interaction between the two types of investments of incumbents, R\&D and raising rivals' costs.

Finally, suppose that, at the stage of the investment decision of incumbents (choosing $l$ and $b$ ) and the entry decision of potential entrants, profits arising at the product market competition stage, called "current profits", may be discounted. The discount factor is denoted by $\rho \in(0,1]$. This is inconsequential for the analysis of the basic model but, as will become apparent, makes it directly comparable to the dynamic model in section 4.

\subsection{Equilibrium Analysis}

An equilibrium in the economy can be derived by solving the following steps. First, we derive current profits by looking at the Cournot-Nash equilibrium in the product market, for a given number of firms and given product quality levels. Second, we examine the viable number of entrants in the industry, $m$, who enter as long as (discounted) current profits cover the entry costs, given both the R\&D investment, $l$, and anticompetitive effort, $b$, of the incumbent. Third, we consider the incumbents' optimal choice of investments, where incumbents take into account the implications of their decisions on both the number of rivals and the resulting outcome from product market competition.

\subsubsection{Profit Functions}

We start by characterizing current profits, given product quality levels of incumbents (depending on R\&D effort $l$ ) and given the number of entrants, $m$. At the product 
market competition stage, each firm $k$ maximizes sales revenue (since marginal production costs are zero), $p_{k} x_{k}$, subject to demand schedule (1), by taking quantities set by other firms as given. We denote by $\pi^{I}$ and $\pi^{E}$ the resulting equilibrium sales revenue of the incumbent and entrants, respectively. The following result holds. (Throughout, subscripts on functions denote partial derivatives.)

Lemma 1. For given $l \geq 0$ and $m>0$, current profits of the incumbent and entrants can be written as $\pi^{I} \equiv \tilde{\pi}^{I}(l, m ; \lambda)$ and $\pi_{t}^{E} \equiv \tilde{\pi}^{E}(l, m ; \lambda)$, respectively, where functions $\tilde{\pi}^{I}$ and $\tilde{\pi}^{E}$ fulfill: $\tilde{\pi}_{l}^{I}>0, \tilde{\pi}_{l}^{E}<0, \tilde{\pi}_{m}^{I}<0, \tilde{\pi}_{m}^{E}<0, \tilde{\pi}_{\lambda}^{I}<0$, and $\tilde{\pi}_{\lambda}^{E}>0$. Moreover, $\tilde{\pi}_{m m}^{I}>0$ and, finally, if $\lambda$ is sufficiently large (small), then $\tilde{\pi}_{l m}^{I}<(>) 0$; if all firms offer the same quality (i.e., $\lambda=g(l)$ ), then $\tilde{\pi}_{l m}^{I}<0$.

Lemma 1 is proven, as all other subsequent formal results, in the Appendix. It says that, first, an increase in $\mathrm{R} \& \mathrm{D}$ effort of the incumbent, $l$, is associated with higher product quality and thus raises her equilibrium revenue $\left(\tilde{\pi}_{l}^{I}>0\right)$. However, as product demand is redistributed away from rivals, it lowers current profits of entrants $\left(\tilde{\pi}_{l}^{E}<0\right)$. An increase in the number of entrants, $m$, lowers all firms' current profits $\left(\tilde{\pi}_{m}^{I}<0\right.$, $\tilde{\pi}_{m}^{E}<0$ ). Moreover, if entrants offer higher product quality (higher $\lambda$ ), then their revenue increases $\left(\tilde{\pi}_{\lambda}^{E}>0\right)$, at the expense of incumbents' revenue $\left(\tilde{\pi}_{\lambda}^{I}<0\right)$.

The signs of $\tilde{\pi}_{m m}^{I}$ and $\tilde{\pi}_{l m}^{I}$ in Lemma 1 are of particular interest for the first main result below (Proposition 1). First, a reduction of incumbent's current profit from entry of an additional rival is higher, the lower the number of rivals $\left(\tilde{\pi}_{m m}^{I}>0\right)$. Naturally, for instance, an increase from one to two rivals (an increase of 100 percent) has a higher impact on the incumbent's current profit than an increase from 10 to 11 rivals (an increase of just 10 percent).

The last result in Lemma 1 describes the impact of an increase in the number of entrants on the marginal revenue of an incumbent investing in $R \& D$ (the sign of the cross-derivative $\tilde{\pi}_{l m}^{I}$ ). To interpret it, suppose for the moment that $m$ is exogenous and hence the incumbent only chooses R\&D investments prior to product market competition, as in standard models of endogenous technical change. To consider the number of entrants to be exogenous serves as benchmark for our later results where $m$ depends 
on anti-competitive conduct of incumbents. When all firms are symmetric, in the sense that the incumbent and entrants have the same product quality $(\lambda=g(l))$, then an increase in $m$ unambiguously reduces the incentive of incumbents to invest in $\mathrm{R} \& \mathrm{D}$ $\left(\tilde{\pi}_{l m}^{I}<0\right)$ and thus R\&D effort of incumbents declines (given that initially $l$ was at the optimal level). ${ }^{6}$ This is due to a standard "demand size effect", known from the IO literature on R\&D (e.g., Cohen and Klepper, 1996a,b; Vives, 2004): An increase in the number of firms reduces the demand for each firm, all other things equal. This means that an increase in product quality applies to less output units. Consequently, when firms are symmetric, the return to $R \& D$ is diminished. ${ }^{7}$ For the incumbent, the same is true if $\lambda>g(l)$. However, if the incumbent offers higher product quality than entrants at the optimal $l$, then increased entry may induce the technology leader to mitigate the additional competitive pressure it faces when $m$ increases, by raising R\&D effort $\left(\tilde{\pi}_{l m}^{I}>0\right)$. This allows the incumbent to regain market share, which is clearly only possible under asymmetry of firms.

\subsubsection{R\&D, Raising Rivals' Cost, and Entry}

We now turn to the decision of potential entrants whether or not to penetrate the industry and the decision of the incumbent with respect to both R\&D activity and outlays to raise rivals' cost, $l$ and $b$, respectively.

Entry in any industry occurs as long as the discounted profit are not below entry costs, $\rho \pi^{E} \geq F$. Using Lemma 1 , given the investments $l$ and $b$ of the incumbent, the number of entrants, $m$, is implicitly given by

$$
\rho \tilde{\pi}^{E}(l, m ; \lambda)=F(b ; \chi) .
$$

Lemma 2. For given $l \geq 0$ and $b \geq 0$, the number of entrants can be written as

\footnotetext{
${ }^{6}$ To see this, note that an incumbent chooses R\&D effort, $l$, to maximize discounted revenue minus $\mathrm{R} \& \mathrm{D} \operatorname{costs}, \rho \tilde{\pi}^{I}(l, m ; \lambda)-l$. That is, when the optimal $l$ is interior, it is given by first-order condition $\rho \tilde{\pi}_{l}^{I}(l, m ; \lambda)=1$. Hence, an increase in $m$ raises (lowers) the optimal $l$ when $\tilde{\pi}_{l m}^{I}>(<) 0$.

${ }^{7}$ Vives (2004) demonstrates that this is a robust result in the case of symmetric firms in a large variety of IO models which consider $\mathrm{R} \& \mathrm{D}$ expenditure decisions of firms.
} 
$m \equiv \tilde{m}(l, b ; \lambda, \chi)$, where function $\tilde{m}$ fulfills $\tilde{m}_{l}<0, \tilde{m}_{l b}>0, \tilde{m}_{b}<0$ and $\tilde{m}_{\lambda}>0$.

That $m$ is decreasing in the incumbent's R\&D investment, $l$, all other things being equal, is due to the fact that higher quality of the incumbent's product lowers entrants' current profit (Lemma 1). Hence, incumbents can discourage entry by R\&D. The entry-reducing effect of R\&D is weakened by higher anti-competitive effort $\left(\tilde{m}_{l b}>0\right)$. Moreover, not surprisingly, entry is reduced by higher anti-competitive effort, $b$, of the incumbent and, as $\tilde{\pi}_{\lambda}^{E}>0$ (Lemma 1), raised if product quality $\lambda$ increases.

We next examine how the productivity of anti-competitive behavior, $\chi$, and the quality offered by entrants, $\lambda$, affect R\&D investment of the incumbent firm, its anticompetitive effort, and the equilibrium number of firms. As endogenous sunk costs are given by $l+b$, at the investment stage the incumbent chooses $l$ and $b$ to maximize

$$
\Pi(l, b ; \lambda, \chi) \equiv \rho \tilde{\pi}^{I}(l, \tilde{m}(l, b ; \lambda, \chi) ; \lambda)-l-b .
$$

We focus on interior solutions throughout. ${ }^{8}$ Denoting equilibrium values of R\&D investment, anti-competitive effort and number of entrants by $l^{*}, b^{*}$ and $m^{*}$, respectively, we are now ready to state our first main result:

Proposition 1. An increase in the productivity of competition-impeding activity, $\chi$, not only raises equilibrium anti-competitive effort, $b^{*}$, but also equilibrium investment in RED, $l^{*}$; moreover, the equilibrium number of entrants, $m^{*}$, is decreasing in $\chi$. An increase in $\lambda$ reduces both $l^{*}$ and $b^{*}$, and raises $m^{*}$.

It is not surprising that an increase in the productivity of raising rivals' entry cost, $\chi$, raises competition-impeding activity of incumbents, $b^{*}$. In turn, the upward shift in entry cost lowers the number of entrants. The striking result in Proposition 1, however, is that increased anti-competitive activity goes in parallel with an increase in the R\&D investment of incumbents. Not only $b^{*}$ but also $l^{*}$ is increasing in $\chi$. Also with respect to a change in the product quality of entrants, $\lambda$, investment in raising entry barriers

\footnotetext{
${ }^{8}$ Strict concavity of $\Pi(l, b ; \lambda, \chi)$ as function of $(l, b)$ is ensured if $g$ and $h$ are "sufficiently concave" as a function of choice variables $l$ and $b$, respectively.
} 
and in R\&D are complementary activities of the incumbent in equilibrium. When $\lambda$ increases, both R\&D and anti-competitive effort of the incumbent are discouraged; and consequently, since $\tilde{m}_{\lambda}>0$ (Lemma 2), the number of entrants, $m^{*}$, unambiguously increases. Insofar as $\lambda$ is inversely related to IPR protection, this suggests that stronger protection of IPR (lower $\lambda$ ) leads to higher entry barriers (by inducing the incumbent to raise $b^{*}$ ), in addition to promoting $\mathrm{R} \& \mathrm{D}$ investment, and lowers the number of firms and products.

\subsubsection{Discussion of Basic Mechanism}

We now look more closely into the mechanics which give rise to the - somewhat surprising - complementarity between $\mathrm{R} \& \mathrm{D}$ investment and anti-competitive effort of the incumbent. Notably, this complementarity means that equilibrium R\&D outlays, $l^{*}$, and the equilibrium number of entrants, $m^{*}$, are unambiguously negatively related. This is in stark contrast to the case where we treated the number of entrants as exogenous (Lemma 1). There we saw that an increase in $m$ (stronger competition) depresses R\&D activity if product quality of entrants is similar or better than that of the incumbent, but it actually raises $R \& D$ activity of the incumbent if $\lambda$ is sufficiently low. Hence, comparing Lemma 1 and Proposition 1 suggests that it potentially makes a big difference whether entry barriers are treated as exogenous or endogenous.

To gain insight into why endogenous entry barriers are unambiguously positively related to $\mathrm{R} \& \mathrm{D}$ even when $\tilde{\pi}_{l m}^{I}>0$ holds, let us first consider the marginal profit of incumbents when raising R\&D effort. According to (5), we have

$$
\Pi_{l}=\rho\left(\tilde{\pi}_{l}^{I}+\tilde{\pi}_{m}^{I} \tilde{m}_{l}\right)-1
$$

Expression (6) shows that the marginal benefit of R\&D consists of two effects. (Marginal costs of R\&D are unity.) First, increasing product quality "directly" raises current profits $\left(\tilde{\pi}_{l}^{I}>0\right)$, according to Lemma 1 . Second, if the incumbent raises R\&D investment, then entrants' revenue is lowered and thereby entry is discouraged. This additional incentive of incumbents to invest in R\&D may be called the "discouraging- 
entry effect of R\&D".

The key for the result that $l$ and $b$ are complements for the incumbent lies in the property $\Pi_{l b}>0$ (shown in the proof of Proposition 1 in Appendix), which implies that the incentive of incumbents to invest in $\mathrm{R} \& \mathrm{D}$ rises when anti-competitive behavior becomes more attractive for incumbents. To see why this is the case, let us differentiate $\Pi_{l}$ from (6) with respect to $b$, which gives us

$$
\frac{\Pi_{l b}}{\rho}=\tilde{\pi}_{l m}^{I} \tilde{m}_{b}+\tilde{\pi}_{m m}^{I} \tilde{m}_{l} \tilde{m}_{b}+\tilde{\pi}_{m}^{I} \tilde{m}_{l b}
$$

The first term on the right-hand side of (7) shows how the direct incentive of investing in R\&D (captured by term $\tilde{\pi}_{l}^{I}$ in (6)) is affected by an increase in anti-competitive conduct, $b$. When $\tilde{\pi}_{l m}^{I}<0$ the direct marginal benefit of $\mathrm{R} \& \mathrm{D}$ is raised by an increase in $b$, as entry costs increase and thus the number of firms is reduced $\left(\tilde{m}_{b}<0\right)$. But the opposite is true when entrants' technology is sufficiently lagging behind, such that $\tilde{\pi}_{l m}^{I}>0$ (Lemma 1). In this latter case, a lower number of rivals, induced by a higher $b$, reduces the direct $\mathrm{R} \& \mathrm{D}$ incentive of the incumbent. It follows that for the complementarity of R\&D and anti-competitive conduct, driven by $\Pi_{l b}>0$, the impact of an increase in $b$ on the discouraging-entry effect of R\&D (captured by term $\tilde{\pi}_{m}^{I} \tilde{m}_{l}$ in (6)) is crucial, as reflected by the last two terms on the right-hand side of (7). However, by Lemmas 1 and 2, the last term is even negative. The main intuition for Proposition 1 is thus associated with the second term, which is always positive (again, according to Lemmas 1 and 2). The intuition may be described as follows: Reducing entry of rivals by behaving more anti-competitively (recall $\tilde{m}_{b}<0$ ), e.g. after an increase in $\chi$, gives an additional incentive to discourage entry by $\mathrm{R} \& \mathrm{D}$ (recall $\tilde{m}_{l}<0$ ), because the profit-increase from deterring an additional rival is higher, the lower the number of rivals is. Formally, this is the case because of $\tilde{\pi}_{m m}^{I}>0$ (Lemma 1). Similarly, discouraging entry by increasing R\&D investment, e.g. after a decrease in $\lambda$ (stronger IPR protection), gives an additional incentive to behave anti-competitively. As argued above, the critical property $\tilde{\pi}_{m m}^{I}>0$ is intuitive, as it just means that a decrease in the number of rivals by one firm has a larger impact on incumbent's profits, the lower 
$m$ already is. ${ }^{9}$

In sum, in the proposed model, there is an unambiguously positive relationship between anti-competitive investment and $\mathrm{R} \& \mathrm{D}$ effort of an incumbent, where changes in equilibrium values $l^{*}$ and $b^{*}$ are triggered by changes in $\chi$ or $\lambda$. We have shown that this result also holds if higher competitive pressure from an exogenous source (i.e., a higher $m$, when $m$ is treated as parameter) fosters R\&D investment - a possibility which has gained considerable attention in the recent literature on competition and growth (see e.g. the survey in Aghion and Howitt, 2005). As a caveat, the discussion also revealed that under alternative demand schedules or other forms of competition the result may not hold unambiguously. What plays a crucial role is how the discouragingentry effect of $R \& D$ is altered by higher investment in anti-competitive conduct.

\section{R\&D-based Growth and Welfare}

It is straightforward to extend the basic model to a simple endogenous growth framework. This will allow us to examine the implications of Proposition 1 for economic growth and welfare.

\subsection{Extension of the Basic Model}

\subsubsection{Households}

Consider an infinitely-living, representative household, supplying one unit of labor to a perfect labor market. Time is discrete and indexed by $t$. Preferences are represented by the intertemporal utility function

$$
U=\sum_{t=0}^{\infty} \rho^{t} C_{t} .
$$

\footnotetext{
${ }^{9}$ We have checked, for instance, that for symmetric firms this property holds for any demand schedule and constant marginal costs, when the assumption of Cournot competition and horizontally non-differentiated goods is maintained.
} 
The quasi-linear consumption index $C_{t}$ is given by

$$
C_{t}=\int_{0}^{1} Y_{t}(i) d i+B_{t} Z_{t}
$$

where $Z_{t}$ is a numeraire commodity (i.e., its price equals unity, $p_{Z}=1$ ), $B_{t}$ is an indicator of its quality and

$$
Y_{t}(i)=\sum_{k=1}^{N_{t}(i)}\left(q_{k, t}(i) x_{k, t}(i)-\frac{\gamma}{2} x_{k, t}(i)^{2}\right)-\gamma \sum_{k} \sum_{l<k} x_{k, t}(i) x_{l, t}(i)
$$

is a sub-utility function. Goods are produced by a continuum of industries which are indexed by $i \in[0,1]$. Like in the basic model, $x_{k}$ and $q_{k}$ are quantity and quality of good $k \in\{1,2, \ldots, N\}$, respectively. Indices $t$ and $i$ indicate time and industry in which the good is produced, respectively.

We assume that the financial market is perfect. The interest rate, $r$, is exogenously given at $r=1 / \rho-1$ (small open economy). According to intertemporal utility function (8), this implies that households are indifferent between present and future consumption. ${ }^{10}$ Specifications (9) and (10) imply that the demand function for any variety $k$ of industry $i$ at time $t$ can inversely be stated as $p_{k, t}(i)=\left(q_{k, t}(i)-\gamma X_{t}(i)\right) / B_{t}$, where $X_{t}(i)=\sum_{j=1}^{N} x_{t, j}(i)$. This expression is almost identical to the demand schedule in the basic model (where we have considered a single-industry in a static context), (1), besides the explicit consideration of the quality of the numeraire, $B$, implicitly set to unity in section 4 . Our preference specification is basically adopted from the standard quasi-linear utility function in the IO literature (see Sutton, 1998, p. 46), only slightly generalized to allow for a dynamic analysis with multiple industries.

\subsubsection{Firms}

Suppose, without loss of generality, that initially $m_{0}(i)=0$ for all $i \in[0,1]$. Marginal production costs are again set to zero and there is again Cournot competition within

\footnotetext{
${ }^{10}$ Hence, households accommodate any credit demand of firms for investments at the fixed interest rate $r$. This simplifying assumption is common in the literature on R\&D-based growth. See, for instance, Aghion, Howitt and Mayer-Foulkes (2005) for a recent example.
} 
each industry. The numeraire commodity is produced under perfect competition, where one unit of labor can be transformed into one unit of output. Since the labor market is perfectly competitive and the price of $Z_{t}$ is normalized to unity, the wage rate is given by $w_{t}=1$.

Incumbent firms (one in each industry) can incur in-house R\&D labor investments $(l)$ in order to improve product quality one period in advance of production. ${ }^{11}$ An incumbent's product quality, $q_{t}^{I}(i)$, evolves according to $q_{t}^{I}(i)=\bar{A}_{t-1} g\left(l_{t-1}(i)\right)$, where $\bar{A}_{t-1}$ represents the state of knowledge in $t-1$, accessible to all firms. Hence, following Young (1998), among others, knowledge acquired through R\&D is firm-specific (private information) for one period only. For instance, one may think of patent rights which last for one period. Initially, $q_{0}^{I}(i)=\bar{A}_{0}>0$ for all $i \in[0,1]$. In addition to $g^{\prime}>0$ and $g^{\prime \prime}<0$, as assumed in the basic model, let $g(0)=1$, i.e., incumbents' quality remains the same if there is no investment in R\&D. In analogy to (2), for all $i$ and $t \geq 1$, any entrant has product quality $q_{t}^{E}(i)=\lambda \bar{A}_{t-1}$.

Like $R \& D$ resources, anti-competitive effort, $b$, is incurred by incumbents one period in advance of production and is in terms of labor. ${ }^{12}$ That is, the amount $b_{t-1}(i)$ an incumbent $i$ spends in $t-1$ affects the number of rivals in industry $i$ at time $t, m_{t}(i)$, by determining sunk costs, $F\left(b_{t-1}(i) ; \chi\right)$, of rivals. At all times, $F$ has to be incurred by rivals one period in advance to production. (That is, entrants basically have to re-establish each period.)

Note that each firm has power in the goods market, but is of measure zero in the economy (as there is a continuum of industries), consistent with a perfect labor market. Our set up follows Neary (2003a,b) in that we have oligopolistic competition in the product markets and perfect competition in the labor market. However, unlike Neary (2003a,b), we use quasi-linear utility that abstracts from general equilibrium income effects for analytical convenience. ${ }^{13}$

\footnotetext{
${ }^{11}$ Smulders and van de Klundert (1995) have introduced in-house R\&D in endogenous growth theory.

${ }^{12}$ If we assumed, alternatively, that incumbents' inputs $l$ and/or $b$ are in terms of the numeraire good $(Z)$, as implicitly done in the basic model, the analysis would remain unaffected.

${ }^{13}$ We could allow for an interaction between goods markets and the labor market by removing the numeraire commodity from the model (i.e., setting $B=0$ ). According to our focus on the demand for labor in $R \& D$ and anti-competitive conduct, which can reasonably be viewed as a tiny
} 


\subsubsection{Stock of Knowledge}

The dynamics of the model come from the evolution of the stock of knowledge, which accumulates according to

$$
\begin{aligned}
\bar{A}_{t} & =\int_{0}^{1} q_{t}^{I}(i) d i+\mu \int_{0}^{1} m_{t}(i)^{1-\varepsilon} q_{t}^{E}(i) d i \\
& =\bar{A}_{t-1} \int_{0}^{1}\left[g\left(l_{t-1}(i)\right)+\mu \lambda m_{t}(i)^{1-\varepsilon}\right] d i
\end{aligned}
$$

where $\mu \geq 0$ and $0<\varepsilon<1$. (Equation (12) follows from (11) by substituting $q_{t}^{I}(i)=$ $\bar{A}_{t-1} g\left(l_{t-1}(i)\right)$ and $q_{t}^{E}(i)=\lambda \bar{A}_{t-1}$. $)$ According to the first term on the right-hand side of (11), the economy's state of technology depends on the average over the product quality levels of incumbents across industries. If $\mu>0$, the knowledge base is also affected by quality levels of entrants, as captured by the second term. For instance, this case may reflect international technology spillovers of entrants from abroad (e.g. multinationals), from foreign direct investment (FDI). If $\mu=0$, entrants do not contribute to the economy's knowledge base. Whether $\mu>0$ or $\mu=0$ is an empirical question, but critical for the subsequent results.

Insofar as $\mu>0$ captures positive spillover effects of FDI, empirical evidence provides a mixed picture. It is probably fair to say that FDI inflows from developed to developing countries do not induce impressing productivity effects, whereas there is more convincing evidence in support of spillovers between industrial countries. For instance, Borensztein et al. (1998) find that a presumption for positive effects is that the human capital level of the host country exceeds some minimum level. Plant-level evidence for Venezuela by Aitken and Harrison (1999) suggests that positive effects do not exist. Branstetter (2006) provides evidence that Japanese firms which hold FDI capital in the U.S. cite U.S. patents more frequently, which points to positive technology spillovers. Keller and Yeaple (2002) find that 13 percent of productivity growth

fraction of total employment, general equilibrium effects will however be quantitatively unimportant for reasonable specifications. (The fraction of $R \& D$ labor of the workforce is empirically well below 1 percent in most countries.) So the value-added of analyzing general equilibrium effects would be negligible, at the cost of analytical tractability. 
in U.S. manufacturing between 1987 and 1996 can be attributed to FDI spillovers, which they find to occur primarily in $R \& D$ intensive industries. However, the figure is much higher than found in previous studies and no consensus on the magnitude of FDI spillover effects has yet been reached.

To interpret the second term on the right-hand-side of (11) it is useful to distinguish the extreme cases $\varepsilon=0$ and $\varepsilon=1$. If $\varepsilon=0$, this term gives us the average of all $m q^{E}$ across sectors, where $m q^{E}$ is the sum of entrants' quality in each sector $i$. If $\varepsilon=1$, on the other hand, this second term is simply the average product quality level of entrants across industries. If $\mu>0$, then only in the special case $\varepsilon=1$, the number of entrants does not matter for the evolution of knowledge. Consequently, as in the case $\mu=0$, anti-competitive activity of incumbents will not have an impact on the evolution of the knowledge base of firms through impeding entry (that is, by lowering $m)$. However, whenever there are positive spillovers from the incumbents' rivals on the economy $(\mu>0)$ and $\varepsilon<1$, the total number of entering firms matters for the aggregate knowledge stock of the economy. Whether $\varepsilon<1$ or $\varepsilon=1$ is again an empirical question, which has yet to be addressed.

Suppose finally that the quality index $B$ of the good produced by the numeraire sector evolves in parallel with the oligopolistic sectors (capturing cross-sectoral spillovers), according to $B_{t}=\bar{A}_{t-1}^{2}$, where $B_{0}>0$ is given. Together with (12), this implies that the sectoral composition of output remains constant over time and transitional dynamics are eliminated from the model, as will become apparent in the equilibrium analysis, to which we turn next.

\subsection{Equilibrium Analysis}

At the product market competition stage, we look at the period-by-period CournotNash equilibrium. ${ }^{14}$ It is easy to show, analogously to Lemma 1, that current profits

\footnotetext{
${ }^{14}$ One possible justification to focus on the Nash equilibrium of the one-shot Cournot game is that entrants have to re-establish each period. Therefore, the set of entrants is different in any period such that product market competition is not a repeated game. Alternatively, we could assume that the firms' planning horizon is finite.
} 
of incumbents and entrants in each industry $i$ at all periods $t \geq 1$ are given by $\pi_{t}^{I}(i)=$ $\tilde{\pi}^{I}(l, m ; \lambda)$ and $\pi_{t}^{E}(i)=\tilde{\pi}^{E}(l, m ; \lambda)$, respectively, where functions $\tilde{\pi}^{I}$ and $\tilde{\pi}^{E}$ are the ones we characterized in Lemma 1. Thus, current profits are time-invariant. Moreover, analogously to (4), the number of entrants is given by $m_{t}(i)=\tilde{m}\left(l_{t-1}(i), b_{t-1}(i) ; \lambda, \chi\right)$, where function $\tilde{m}$ has been characterized in Lemma 2. Note that, as there is a continuum of sectors, each incumbent firm is small in the sense that it does not take into account the impact of its decisions on the future state of technology, $\bar{A}_{t}$. Investments provide firm-specific benefits for the next period only. Thus, incumbents maximize discounted current profits next period minus investment costs today. Formally, for all $i$ and $t \geq 1$, they again maximize $\Pi(l, b ; \lambda, \chi)$, defined in $(5)$, with respect to $(l, b)$. Again focussing on an interior solution, in equilibrium, $l_{t-1}(i)=l^{*}, b_{t-1}(i)=b^{*}$ and $m_{t}(i)=m^{*}=\tilde{m}\left(l^{*}, b^{*} ; \lambda, \chi\right)$ for all $i$ and $t \geq 1$ and Proposition 1 holds.

Proposition 1 raises important policy questions: First, may an institutional environment which is more conducive for anti-competitive conduct of incumbents (higher $\chi)$ promote growth and raise welfare in an economy, due to positive effects on the equilibrium R\&D effort of incumbents, $l^{*}$ ? Moreover, in view of the positive impact of higher product quality of entrants (higher $\lambda$ ) on the equilibrium number of firms, $m^{*}$, and potentially on the stock of knowledge, according to (12), we may ask if weaker protection of IPR may be conducive to growth. These are the questions we address next.

\subsubsection{Growth effects}

Using that, in equilibrium, $l_{t-1}(i)=l^{*}$ and $m_{t}(i)=m^{*}$ for all $i$ and $t \geq 1,(12)$ implies that the economy's stock of knowledge changes according to

$$
\frac{\bar{A}_{t}}{\bar{A}_{t-1}}=g\left(l^{*}\right)+\mu \cdot \lambda \cdot\left(m^{*}\right)^{1-\varepsilon} \equiv \Lambda\left(l^{*}, m^{*} ; \lambda\right) .
$$

The implication for the growth rate of the consumption index, $\vartheta_{t} \equiv C_{t} / C_{t-1}-1$, is given by 
Lemma 3. In equilibrium, $\vartheta_{t}=\Lambda\left(l^{*}, m^{*} ; \lambda\right)^{2}-1 \equiv \vartheta^{*}$ for all $t \geq 2$.

As $g(0)=1$ and $g^{\prime}>0$, using (13), Lemma 3 implies that $\vartheta^{*}>0$. As a corollary to Proposition 1 and Lemma 3, we find

Proposition 2. An increase in the productivity of competition-impeding activity, $\chi$, raises the steady state growth rate $\vartheta^{*}$ when $\mu=0$ or $\varepsilon=1$. When $\mu>0$ and $\varepsilon<1$, the impact of an increase in $\chi$ on $\vartheta^{*}$ is ambiguous. When $\mu=(>) 0$, the impact of higher quality of entrants' products, $\lambda$, on $\vartheta^{*}$ is negative (ambiguous).

Proposition 2 highlights that growth effects of incumbents' behavior depend on the existence and nature of spillover effects from entrants to the economy's knowledge base. Let us first discuss a change in $\chi$, when there are no spillover effects on aggregate knowledge from market penetration $(\mu=0)$ or if the number of entrants does not matter for the knowledge base $(\varepsilon=1)$. In these cases, the reduction in the equilibrium number of entrants, $m^{*}$, in response to an increase in $\chi$ (Proposition 1 ) is inconsequential for growth. Hence, since an increase in $\chi$ not only raises incumbents' anti-competitive effort $\left(b^{*}\right)$ but also $\mathrm{R} \& \mathrm{D}$ investment $\left(l^{*}\right)$, our analysis suggests that the growth rate may be higher when the economy's political and regulatory institutions encourage activity of incumbents to raise rivals' cost.

However, if there are positive externalities $(\mu>0)$, say, from FDI and if the spillovers are higher the more firms enter the economy $(\varepsilon<1)$, competition-impeding activity may very well be harmful for an economy's R\&D-based growth process. As a policy implication, this would call for sanctioning of anti-competitive conduct of incumbents (thus reducing $\chi$ ), even if $\mathrm{R} \& \mathrm{D}$ and anti-competitive conduct were complementary from the perspective of incumbents. As mentioned above, whether or not FDI spillovers exist, for instance, and to what extent, is still under debate.

An increase in the quality of entrants' products (higher $\lambda$ ) generally has an ambiguous effect on growth as well. On the one hand, incumbents reduce R\&D effort, $l^{*}$, according to Proposition 1. On the other hand, if $\mu>0$, an increase in $\lambda$ positively affects the economy's knowledge base. Hence, a higher product quality of entrants may 
well be conducive for growth. This is more likely in the case where $\varepsilon<1$ than in the case $\varepsilon=1$, since we found that the equilibrium number of entrants, $m^{*}$, is increasing in $\lambda$.

Insofar as the quality of entrants is inversely related to the strength of IPR, Proposition 2 raises the possibility that weaker protection of IPR may foster growth. However, this cannot be the case if entrants purely imitate (perfectly or imperfectly) incumbents' technology; for weaker IPR to have positive growth effects, entrants must truly add to the economy's stock of knowledge, e.g., through own R\&D. An extension to our analysis (not presented due to space limitations) raises doubts that this will be the case. We have allowed entrants to invest in R\&D, assuming that incumbents are Stackelberg leaders and entrants are followers at the strategic investment stage. More precisely, we specified $\lambda=\xi g\left(d_{t-1}(i)\right)$, where $d$ is R\&D investment of an entrant and $\xi \in(0,1]$ may be interpreted as inversely measuring the strength of IPR in this extended version of the model, as a higher $\xi$ allows entrants to access a higher state of technology. Numerical analysis suggests that the results regarding the impact of a higher $\chi$ in Proposition 1 still hold. Moreover, we find that an increase in $\chi$ raises equilibrium R\&D investment of entrants $\left(d^{*}\right)$. However, R\&D investments of both incumbents and entrants are decreasing in $\xi$. Thus, by endogenizing R\&D investments of entrants as well, the analysis suggests that stronger protection of IPR unambiguously spurs growth.

\subsubsection{Welfare Effects}

We finally turn to welfare effects of both changes in the productivity of anti-competitive conduct, $\chi$, and changes in the product quality of entrants, $\lambda$. For a given knowledge base, given product quality levels of incumbents, and a given number of firms, higher product quality of entrants naturally has a positive welfare effect. Propositions 1 and 2 suggest that there are several more indirect and potentially counteracting welfare effects of changes in $\chi$ or $\lambda$. First, there are dynamic effects from changes in the (steady state) growth rate, $\vartheta^{*}$. Growth rate $\vartheta^{*}$ is positively related to the incumbents' R\&D investment, $l^{*}$, where $l^{*}$ rises if $\chi$ increases or if $\lambda$ decreases. Moreover, if there are 
positive knowledge spillover effects from entrants $(\mu>0), \vartheta^{*}$ is positively related to entrants' quality, and thus to $\lambda$. If $\varepsilon<1, \vartheta^{*}$ also depends on the number of firms, where $m^{*}$ is decreasing in $\chi$ and increasing in $\lambda$. Second, however, there are static distortions from oligopoly competition. An increase in $\chi$, by lowering the equilibrium number of firms, accentuates these distortions. An increase in $\lambda$ has the opposite effect, by raising $m^{*}$. Third, any increase in incumbents' R\&D investment or effort to raise rivals' cost implies that production of the numeraire good, $Z$, declines. As $l^{*}$ and $b^{*}$ increase in $\chi$ and decrease in $\lambda$, through this effect on numeraire good consumption, an increase in $\chi$ has a negative and an increase in $\lambda$ has a positive welfare effect. Regarding $b^{*}$, this effect reflects that anti-competitive conduct is a socially wasteful activity in the sense that it affects quantity and quality levels of consumption goods only through its interaction with $\mathrm{R} \& \mathrm{D}$ and by changing the number of entrants.
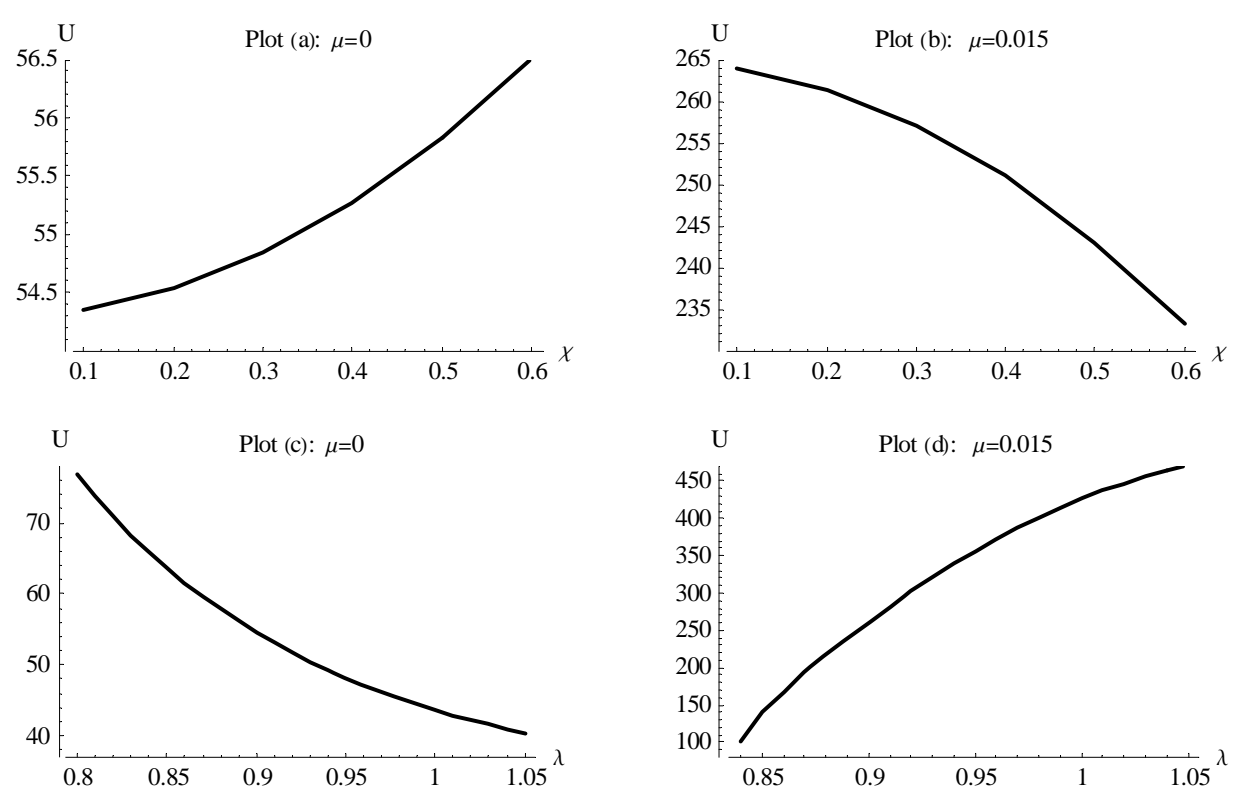

Figure 1: Welfare as a function of key model parameters $\chi$ and $\lambda$. The underlying set of parameters reads: $\overline{\mathrm{A}}_{0}=\overline{\mathrm{B}}_{0}=1, \mathrm{r}=0.06, \mathrm{f}=0.1, \eta=0.2, \kappa=0.2, \varepsilon=0.7$. For plot (a) and (b) $\lambda=0.9$, whereas plot (c) and (d) assume $\chi=0.2$.

Fig. 1 plots equilibrium welfare as function of $\chi$ (panels (a) and (b)) and $\lambda$ (panels (c) and (d)), by specifying $g(l)=1+\eta l^{0.5}, h(b)=\kappa b^{0.5}$, and choosing parameters 
such that welfare is finite. ${ }^{15}$ Panels (a) and (c) show a situation where there are no technological spillovers from entrants, captured by setting $\mu=0$. The numerical results suggest that in this case an increase in the productivity of competition-impeding conduct or a decrease in product quality of entrants may raise welfare. Intuitively, according to the discussion above, the positive effects of a higher $\chi$ or a lower $\lambda$ on incumbents' R\&D investment (Proposition 1) and therefore on growth (Proposition 2) dominate the static welfare losses of consumers because of stronger oligopoly distortions and reduced consumption of the numeraire good. (In case of a decrease in $\lambda$, there is also a direct static welfare effect as available products of entrants are of lower quality.) However, according to panels (b) and (d) in Fig. 1, the situation may change if there are positive knowledge spillover effects from entrants $(\mu>0)$ and the number of entrants matters for these dynamic effects $(\varepsilon<1)$, holding other parameter values constant. In this case, welfare may well be a decreasing function of $\chi$ (panel (b)) and an increasing function of $\lambda$ (panel $(\mathrm{d})$ ), despite the fact that incumbents' R\&D investment $\left(l^{*}\right)$ rises in $\chi$ and declines in $\lambda$.

\section{The Case of South Korea}

Finally, we sketch a real-world macroeconomic development process which features some aspects that point to the importance of the mechanisms discussed above. The Republic of Korea, once one of the world's poorest agrarian societies, has undertaken an outstanding economic development since 1965. The annual growth rate of per capita income during the period 1965 until 2000 averaged to about 6.6\% (Heston et al., 2002). South Korea is known to have pursued an interventionist approach based on an outward oriented development strategy, combined with trade protection, and several policies which directly or indirectly promoted R\&D. There is strong evidence showing that $\mathrm{R} \& \mathrm{D}$ has played an important and increasing role in this process. The R\&D intensity (GERD as percentage of GDP) rose from $1.9 \%$ in 1991 to $2.7 \%$ in 2000,

\footnotetext{
${ }^{15}$ The analytical expressions which form the basis of our numerical analysis are available upon request. Inter alia, there we have shown that welfare $U$ is finite if and only if $\rho \Lambda^{2}<1$ in equilibrium.
} 
which was about the same value as in the U.S. at that time. Moreover, Korean R\&D is financed and performed overwhelmingly by the business sector. The share of GERD financed by industry peaked at $78 \%$ in 1996, dipped below $70 \%$ during the financial crises, and returned to $72 \%$ by 2000 . This figure is highest in the OECD, equalled only by Japan (OECD, 2002, p. 15).

South Korea is also known to exhibit a high degree of product market regulation. Conway et al. (2005, p. 12) classify South Korea as following a "relatively restrictive" product market competition regime. More precisely, in the subcategories which capture barriers to entrepreneurship, "administrative burden" and "legal barriers", South Korea is among the most restrictive countries (Conway et al., 2005, p. 54). Turning to competition intensity, Yongchun et al. (2004, p. 6) report that average industry concentration, measured by the Hirschman-Herfindahl index, is particularly high compared to international standards. From 1977 to 1994, the 30 largest chaebol (large conglomerate firms) accounted for between $32 \%$ and $40 \%$ of total national output. According to the Asian Development Outlook (2005, p. 254) "these large firms used their market power at home to frustrate entry by rivals. [...] Early efforts to introduce competition laws in the country were easily thwarted by lobbying from the corporate sector...". Moreover, Yongchun et al. (2004, p. 19) note that "Korea's government-driven growth policy has included regulations [....] that resulted in various entry barriers, such as licensing, permission, nomination, government monopoly and reporting requirement. According to a government study, 63\% of all industries had regulations controlling market entry."16 The picture is completed by noting that foreign direct investment inflows played a minor role in South Korea prior to 1997, reflecting a generally hostile attitude toward foreign investors (Yongchun et al., 2004, p. 12).

This overall picture clearly suggests the following stylized facts. First, Korean economic growth was significantly fuelled by private business R\&D, conducted in highly concentrated industries. Second, there seems to be a positive interaction between

\footnotetext{
${ }^{16}$ Land-use regulations play a crucial role since South Korea has the third highest population density in the world. The extensive controls on land use, combined with government policies that limit the available supply, can act as significant entry barriers (Yongchun et al., 2004, p. 20).
} 
private business $R \& D$ and anti-competitive activities of incumbent firms. Third, the institutional and regulatory framework appears to have played a major role in enabling private firms to erect market entry barriers.

\section{Conclusion}

In this paper we proposed a simple oligopoly model to investigate the interplay between R\&D investments and expenditure for anti-competitive activities by incumbent firms, and its implications for R\&D-based growth and welfare. Our results support the possibility of a positive relationship between R\&D activity and effort of incumbents to raise rivals' entry cost. Retarded entry by anti-competitive conduct changes incumbents' incentives to incur R\&D costs in two ways. On the one hand, it changes the incentive to invest in $\mathrm{R} \& \mathrm{D}$ which comes from the motivation to increase goods demand for a given number of rivals (the "direct" effect of $R \& D$ ). On the other hand, it also changes the incentive of incumbents to invest in R\&D in order to discourage entry of potential rivals. The change of this discouraging-entry effect of $R \& D$ is critical for the possible complementarity between $R \& D$ investment and anti-competitive expenditure of incumbents. We have argued that this complementarity is not driven by the, from an empirical point of view problematic, prediction of $R \& D$ models with symmetric firms that an exogenous increase in the intensity of product market competition is harmful for innovative activity. In our model, if the number of rivals rises for exogenous reasons (unrelated to incumbents' behavior), then R\&D investment of incumbents is fostered when incumbents are technologically advanced, in line with recent evidence by Aghion et al. (2006).

Turning to the policy implications, we arrive at the following conclusions. Our model points to a specific mechanism according to which the institutional framework or technological possibilities which encourage anti-competitive conduct of incumbent firms may foster R\&D and growth. However, the decrease in the number of rivals induced by both higher anti-competitive activity and R\&D investments of incumbent firms may well imply that long-run growth and welfare are depressed, due to retarded 
knowledge spillovers and stronger oligopoly distortions. Hence, the analysis suggests that the extent and nature of (international) knowledge spillovers is critical to evaluate the net effect of higher incentives for incumbents to invest in raising rivals' entry cost on growth and welfare. We have also argued that, in contrast, stronger protection of intellectual property rights, although impeding market entry as well, is likely to foster economic growth.

\section{Appendix}

Proof of Lemma 1: Using (1), for given quality levels, sales revenue of firm $k$ under Cournot competition is given by

$$
\pi_{k} \equiv \max _{x_{k}} \underbrace{\left(q_{k}-\gamma x_{k}-\gamma \sum_{j \neq k} x_{j}\right)}_{=p_{k}} x_{k}
$$

Solving the first-order condition for $x_{k}$, we obtain $x_{k}=q_{k} / \gamma-X$, where $X=\sum_{j=1}^{N} x_{j}$. Summing both sides over all $k$ and solving for $X$ gives us

$$
X=\frac{\sum_{k=1}^{N} q_{k}}{\gamma(N+1)} .
$$

Using $x_{k}=q_{k} / \gamma-X$, we find

$$
x_{k}=\frac{N q_{k}-\sum_{l \neq k} q_{l}}{\gamma(N+1)} .
$$

Inserting $X$ from (A.2) into (1) and using (A.3) reveals that $p_{k}=\gamma x_{k}$. Consequently, $\pi_{k}=\gamma x_{k}^{2}$. Substituting $x_{k}$ from (A.3), we find

$$
\pi_{k}=\frac{1}{\gamma}\left[\frac{N q_{k}-\sum_{j \neq k} q_{j}}{N+1}\right]^{2} .
$$


Now, using $N=1+m$ together with (2) it is straightforward to check that profits of incumbents and entrants read

$$
\pi^{I}=\frac{1}{\gamma}\left[\frac{g(l)+m(g(l)-\lambda)}{2+m}\right]^{2} \equiv \tilde{\pi}^{I}(l, m ; \lambda)
$$

and

$$
\pi^{E}=\frac{1}{\gamma}\left[\frac{2 \lambda-g(l)}{2+m}\right]^{2} \equiv \tilde{\pi}^{E}(l, m ; \lambda),
$$

respectively. We implicitly assume parameter configurations such that $\pi^{I}>0$ and $\pi^{E}>0$ throughout. For $\pi^{I}>0,($ A.5) implies that condition $\lambda<g(l)(1+1 / m) \equiv \bar{\lambda}$ must hold. For $\pi^{E}>0$, (A.6) implies that condition $\lambda>g(l) / 2 \equiv \underline{\lambda}$ must hold. It will become apparent, in Proposition 1, that equilibrium R\&D investment is decreasing in $\lambda$ and the equilibrium number of firms is increasing in $\lambda$. Thus, in equilibrium, both $\bar{\lambda}$ and $\underline{\lambda}$ are decreasing $\lambda$. This implies that there exists both a unique $\overline{\bar{\lambda}}$ defined by $\lambda=\bar{\lambda}$ and a unique $\underline{\underline{\lambda}}$ defined by $\lambda=\underline{\lambda}$. Hence, there exist both an upper bound for $\lambda$ such that incumbents are viable and a lower bound for $\lambda$ such that entering firms are viable (i.e., $\underline{=}<\lambda<\overline{\bar{\lambda}}$ must hold), as stated in the exposition of the model (section 3 ). Comparative-static results regarding $\tilde{\pi}^{E}$ immediately follow from (A.6). To confirm comparative-static results regarding $\tilde{\pi}^{I}$, use (A.5) to obtain

$$
\tilde{\pi}_{m}^{I}(l, m ; \lambda)=-\frac{2[g(l)+m(g(l)-\lambda)][2 \lambda-g(l)]}{\gamma(2+m)^{3}} .
$$

The first term in square brackets is positive when $\tilde{\pi}^{I}>0$ and the second term is positive when $\tilde{\pi}^{E}>0$. Thus, $\tilde{\pi}_{m}^{I}<0$. Moreover, using (A.7), we obtain

$$
\begin{gathered}
\tilde{\pi}_{m m}^{I}=\frac{2(2[g(l)+m(g(l)-\lambda)]+2 \lambda-g(l))[2 \lambda-g(l)]}{\gamma(2+m)^{4}}, \\
\tilde{\pi}_{l m}^{I}=\frac{2 g^{\prime}(l)}{\gamma(2+m)^{3}}(g(l)+m(g(l)-\lambda)-(1+m)[2 \lambda-g(l)]) .
\end{gathered}
$$

According to (A.8), whenever $\pi^{I}>0$ (i.e., $\left.g(l)+m(g(l)-\lambda)>0\right)$ and $\pi^{E}>0$ (i.e., $2 \lambda>g(l))$, we have $\tilde{\pi}_{m m}^{I}>0$. According to (A.9), $\tilde{\pi}_{l m}^{I}>0$ if $2 \lambda-g(l)$ is close to zero. 
Moreover, if $\lambda=g(l)$, then $\tilde{\pi}_{l m}^{I}<0$. As $\tilde{\pi}_{l m}^{I}$ is decreasing in $\lambda$, this also implies that $\tilde{\pi}_{l m}^{I}<0$ for $\lambda>g(l)$. The remaining comparative-static results immediately follow from (A.5). This concludes the proof.

Proof of Lemma 2. Recall from (4) that $\rho \tilde{\pi}^{E}(l, m ; \lambda)=F(b ; \chi)$ in equilibrium. Using both (3) and (A.6) and solving for $m$ gives us

$$
m=\frac{2 \lambda-g(l)}{\sqrt{\frac{\gamma}{\rho}[f+\chi h(b)]}}-2 \equiv \tilde{m}(l, b ; \lambda, \chi)
$$

Comparative-static results immediately follow from (A.10).

Proof of Proposition 1. Inserting $m$ from (A.10) into (A.5), using (3), and rearranging terms leads to

$$
\pi^{I}=\tilde{\pi}^{I}(l, \tilde{m}(l, b ; \lambda, \chi) ; \lambda)=\frac{1}{\gamma}\left(\sqrt{\frac{\gamma}{\rho}[f+\chi h(b)]}+g(l)-\lambda\right)^{2} .
$$

Hence, using $\Pi=\rho \pi^{I}-l-b, l^{*}$ and $b^{*}$ are simultaneously given by first-order conditions

$$
\begin{gathered}
{\left[\Pi_{l}=\right] \frac{2 \rho}{\gamma}\left(\sqrt{\frac{\gamma}{\rho}[f+\chi h(b)]}+g(l)-\lambda\right) g^{\prime}(l)-1=0,} \\
{\left[\Pi_{b}=\right] \frac{\left(\sqrt{\frac{\gamma}{\rho}[f+\chi h(b)]}+g(l)-\lambda\right) h^{\prime}(b)}{\sqrt{\frac{\gamma}{\rho}\left[\frac{f}{\chi^{2}}+\frac{h(b)}{\chi}\right]}}-1=0 .}
\end{gathered}
$$

Note that $\sqrt{\frac{\gamma}{\rho}[f+\chi h(b)]}+g(l)-\lambda>0$ for $\pi^{I}>0$ to hold, according to (A.11). Thus, considering (A.12) reveals that $\Pi_{l \chi}>0, \Pi_{l \lambda}<0$ and $\Pi_{l b}>0$, whereas (A.13) gives us $\Pi_{b \chi}>0$ and $\Pi_{b \lambda}<0$. Moreover, notice that strict concavity of profit function $\Pi$ implies $\Pi_{b b}<0, \Pi_{l l}<0$ and $\Pi_{l l} \Pi_{b b}-\Pi_{l b}^{2}>0$. Invoking Cramer's rule, this leads to the following comparative-static results:

$$
\operatorname{sgn}\left(\frac{\partial l^{*}}{\partial \chi}\right)=\operatorname{sgn}\left(-\Pi_{l \chi} \Pi_{b b}+\Pi_{l b} \Pi_{b \chi}\right)>0
$$




$$
\begin{aligned}
& \operatorname{sgn}\left(\frac{\partial l^{*}}{\partial \lambda}\right)=\operatorname{sgn}\left(-\Pi_{l \lambda} \Pi_{b b}+\Pi_{b \lambda} \Pi_{l b}\right)<0, \\
& \operatorname{sgn}\left(\frac{\partial b^{*}}{\partial \chi}\right)=\operatorname{sgn}\left(-\Pi_{l l} \Pi_{b \chi}+\Pi_{b l} \Pi_{l \chi}\right)>0, \\
& \operatorname{sgn}\left(\frac{\partial b^{*}}{\partial \lambda}\right)=\operatorname{sgn}\left(-\Pi_{l l} \Pi_{b \lambda}+\Pi_{b l} \Pi_{l \lambda}\right)<0 .
\end{aligned}
$$

Finally, applying (A.14)-(A.17), the comparative-static results regarding $m^{*}=\tilde{m}\left(l^{*}, b^{*} ; \lambda, \chi\right)$ follow from (A.10). This concludes the proof.

Proof of Lemma 3. First, note that the symmetry implies that for all $i$, output is the same among incumbents and among entrants, which we denote by $x_{t}^{I *}$ and $x_{t}^{E *}$, respectively, $t \geq 1$. Using (10) together with the facts that, in equilibrium, for all $i$ and $t \geq 1$, we have $N_{t}(i)=1+m^{*}, q_{t}^{I}(i)=\bar{A}_{t-1} g\left(l^{*}\right) \equiv q_{t}^{I *}$ and $q_{t}^{E}(i)=\lambda \bar{A}_{t-1} \equiv q_{t}^{E *}$, we then find

$$
Y_{t}(i)=q_{t}^{I *} x_{t}^{I *}-\frac{\gamma}{2}\left(x_{t}^{I *}\right)^{2}+m^{*}\left[q_{t}^{E *} x_{t}^{E *}-\left(x_{t}^{E *}\right)^{2}\right]-\gamma m^{*} x_{t}^{E *}\left[x_{t}^{I *}+\frac{m^{*}-1}{2} x_{t}^{E *}\right]
$$

for all $i, t \geq 1$. Moreover, (A.3) implies that

$$
\begin{gathered}
\frac{x_{t}^{I *}}{\bar{A}_{t-1}}=\frac{\left(m^{*}+1\right) g\left(l^{*}\right)-m^{*} \lambda}{\gamma\left(2+m^{*}\right)} \equiv \tilde{x}^{I}\left(l^{*}, m^{*} ; \lambda\right), \\
\frac{x_{t}^{E *}}{\bar{A}_{t-1}}=\frac{2 \lambda-g\left(l^{*}\right)}{\gamma\left(2+m^{*}\right)} \equiv \tilde{x}^{E}\left(l^{*}, m^{*} ; \lambda\right) .
\end{gathered}
$$

Hence, using (A.18)-(A.20), $\bar{A}_{t-1}=\Lambda\left(l^{*}, m^{*} ; \lambda\right)^{t-1} \bar{A}_{0}$ from (13) and $B_{t}=\left(\bar{A}_{t-1}\right)^{2}$, we have

$$
C_{t}=\bar{A}_{0}^{2} \Lambda\left(l^{*}, m^{*} ; \lambda\right)^{2(t-1)} \Theta\left(l^{*}, m^{*} ; \lambda\right)
$$

for $t \geq 1$, according to (9), where

$$
\begin{aligned}
\Theta\left(l^{*}, m^{*} ; \lambda\right) \equiv & 1-l^{*}-b^{*}+g\left(l^{*}\right) \tilde{x}^{I}\left(l^{*}, m^{*} ; \lambda\right)-\frac{\gamma}{2} \tilde{x}^{I}\left(l^{*}, m^{*} ; \lambda\right)^{2}+ \\
& m^{*}\left[\lambda \tilde{x}^{E}\left(l^{*}, m^{*} ; \lambda\right)-\frac{\gamma}{2} \tilde{x}^{E}\left(l^{*}, m^{*} ; \lambda\right)^{2}\right]- \\
& \gamma m^{*}\left[\tilde{x}^{I}\left(l^{*}, m^{*} ; \lambda\right) \tilde{x}^{E}\left(l^{*}, m^{*} ; \lambda\right)+\frac{m^{*}-1}{2} \tilde{x}^{E}\left(l^{*}, m^{*} ; \lambda\right)^{2}\right] .
\end{aligned}
$$


Lemma 3 then follows from expression (A.21).

\section{References}

Acemoglu, Daron, Philippe Aghion and Fabrizio Zilibotti (2006). Distance to Frontier,

Selection, and Economic Growth, Journal of the European Economic Association 4, 37-74.

Aghion, Philippe and Peter Howitt, (2005). Growth with Quality-improving Innovations: An Integrated Framework, in: P. Aghion and S. Durlauf (eds.), Handbook of Economic Growth, pp. 67-110, Amsterdam: North-Holland.

Aghion, Philippe, Peter Howitt and David Mayer-Foulkes (2005). The Effect of Financial Development on Convergence: Theory and Evidence, Quarterly Journal of Economics 120, 173-222.

Aghion, Philippe, Nicolas Bloom, Richard Blundell, Rachel Griffith and Peter Howitt (2005). Competition and Innovation: An Inverted U Relationship, Quarterly Journal of Economics 120, 701-728.

Aghion, Philippe, Richard Blundell, Rachel Griffith, Peter Howitt and Susanne Prantl (2006). The Effects of Entry on Incumbent Innovation and Productivity, Harvard University (mimeo).

Aitken, Brian J. and Ann Harrison (1999). Do Domestic Firms Benefit from Foreign Direct Investment?, American Economic Review 89, 605-618.

Borensztein, Eduardo, Jose De Gregorio and Jong-Wha Lee (1998). How Does Foreign Direct Investment Affect Economic Growth, Journal of International Economics 45, 115-135.

Asian Development Bank (2005). Asian Development Outlook 2005, Mandaluyong City.

Branstetter, Lee (2006). Is Foreign Direct Investment a Channel of Knowledge Spillovers? Evidence from Japan's FDI in the United States, Journal of International Economics 68, 325-344. 
Caves, Richard (1998). Industrial Organization and New Finding on the Turnover and Mobility of Firms, Journal of Economic Literature 36, 1947-1982.

Cohen, Wesley M. and Steve Klepper (1996a). A Reprise of Firm Size and R\&D, Economic Journal 106, 925-951.

Cohen, Wesley M. and Steve Klepper (1996b). Firm Size and the Nature of Innovation Within Industries: The Case of Process and Product R\&D, Review of Economics and Statistics 78, 232-243.

Conway, Paul, Véronique Janod and Giuseppe Nicoletti (2005). Product Market Regulation in OECD countries: 1998-2003, OECD Economics Department Working Papers No. 419, Paris.

Djankov, Simeon, Rafael La Porta, Florenzio Lopez-de-Silanes and Andrei Shleifer (2002). The Regulation of Entry, Quarterly Journal of Economics 116, 1-37.

The Economist (2006). Apples are not the only Fruit: The Economics of France's Attempt to Open Up iTunes, July 8th 2006, p. 75.

Egger, Hartmut, Peter Egger and Volker Grossmann (2006). Does Capital Mobility Promote Economic Growth? The Link to Education, Journal of Financial Transformation 17, 28-31.

Fisher, Franklin M. and Daniel L. Rubinfeld (2001). U.S. v. Microsoft - An Economic Analysis, Antitrust Bulletin 46, 1-69.

Gilbert, Richard J. (1989). Mobility Barriers and the Value of Incumbency, in: Schmalensee, R., Willig, R.D. (eds.), Handbook of Industrial Organization, Vol. I, North-Holland, Amsterdam.

Grossmann, Volker (2007). Advertising, In-house R\&D, and Growth, Oxford Economic Papers, forthcoming.

Infras, Basys (2002). Auswirkungen staatlicher Eingriffe auf Preisniveau im Bereich Humanarzneimittel, Im Auftrag des Schweizer Bundesrats: Generalsekretariat EVD, Bern.

Heston, Alan, Robert Summers and Bettina Aten, Penn World Table Version 6.1, Center for International Comparisons at the University of Pennsylvania (CICUP), Oc- 
tober 2002.

Keller, Wolfgang (2004). International Technology Diffusion, Journal of Economic Literature $42,752-782$.

Keller, Wolfgang and Stephen R. Yeaple (2002). Multinational Enterprises, International Trade, and Productivity Growth: Firm-level Evidence from the United States, University of Texas (mimeo).

Van de Klundert, Theo and Sjak Smulders (1997). Growth, Competition and Welfare, Scandinavian Journal of Economics 99, 99-118.

Krattenmaker, Thomas G. and Steven C. Salop (1986). Anticompetitive Exclusion: Raising Rivals' Costs to Achieve Power over Price, Yale Law Journal 96, 209-293.

OECD (2002). Changing Strategies for Business R\&D and Their Implications for Science and technology Policy in Korea, OECD Country Report, Paris.

Rios-Rull, Jose-Victor and Per Krusell (1996). Vested Interests in a Positive Theory of Stagnation and Growth, Review of Economic Studies 63, 301-329.

Neary, Peter (2003a). International Trade in General Oligopolistic Equilibrium, University College Dublin (mimeo).

Neary, Peter (2003b). Globalisation and Market Structure, Journal of the European Economic Association 1, 245-271.

Salop, Steven C. and David T. Scheffman (1983). Raising Rivals' Costs, American Economic Review Papers and Proceedings 73, 267-271.

Salop, Steven C. and David T. Scheffman (1987). Cost-Raising Strategies, Journal of Industrial Economics 36, 19-34.

Stigler, George J. (1971). The Theory of Economic Regulation, Bell Journal of Economics and Management Science 2, 3-21.

Smulders, Sjak and Theo van de Klundert (1995). Imperfect Competition, Concentration and Growth with Firm-Specific R\&D, European Economic Review, 39, 139-160.

Sutton, John (1998). Technology and Market Structure, MIT Press, Cambridge (MA).

Vives, Xavier (2004). Innovation and Competitive Pressure, CEPR Discussion 
Paper No. 4369.

Yongchun, B., R. Jones, and M. Wise, Product Market Competition and Economic Performance in Korea (2004). OECD Economics Department Working Paper No. 399.

Young, Alwyn (1998). Growth Without Scale Effects, Journal of Political Economy $106,41-63$.

\section{Supplement for Numerical Analysis (not to be published)}

This supplement derives the indirect utility function of the representative agent, which forms the basis for our numerical analysis in section 5. We start with an expression for initial consumption index, $C_{0}$. According to (10) and (A.3), since $m_{0}(i)=0$ (i.e., $\left.N_{0}(i)=1\right)$ and $q_{0}^{I}(i)=\bar{A}_{0}>0$ for all $i$, we have $Y_{0}(i)=\frac{3 \bar{A}_{0}^{2}}{8 \gamma}$ for all $i$. Moreover, since $l_{t-1}(i)=l^{*}$ and $b_{t-1}(i)=b^{*}$ for all $t$ and $i$ and the total labor force equals unity, the numeraire sector produces an amount

$$
Z_{t}=1-l^{*}-b^{*}
$$

in $t \geq 0$. Using (9), we find

$$
C_{0}=\frac{3 \bar{A}_{0}^{2}}{8 \gamma}+B_{0}\left(1-l^{*}-b^{*}\right) \equiv \tilde{C}_{0}\left(l^{*}, b^{*}\right)
$$

Substituting (A.21) into (8) and using the fact that $\sum_{t=1}^{\infty} a^{t}=a /(1-a)$ when $|a|<1$, it is easy to check that equilibrium welfare reads

$$
U=\tilde{C}_{0}\left(l^{*}, b^{*}\right)+\bar{A}_{0}^{2} \frac{\rho \Theta\left(l^{*}, m^{*} ; \lambda\right)}{1-\rho \Lambda\left(l^{*}, m^{*} ; \lambda\right)^{2}},
$$

provided that $\rho \Lambda^{2}<1$. Substituting (A.22) and (B.2) into (B.3), and omitting super- 
script $(*)$, we obtain

$$
\begin{aligned}
U= & \frac{3 \bar{A}_{0}^{2}}{8 \gamma}+B_{0}(1-l-b)+\frac{\rho \bar{A}_{0}^{2}}{1-\rho\left[g(l)+\lambda \mu m^{1-\varepsilon}\right]^{2}} \times \\
& \left\{1-l-b+\frac{g(l)[(m+1) g(l)-m \lambda]}{\gamma(2+m)}-\frac{1}{2 \gamma}\left(\frac{(m+1) g(l)-m \lambda}{2+m}\right)^{2}+\right. \\
& \left.\left.\frac{m[2 \lambda-g(l)]}{\gamma}\left[\frac{\lambda}{2+m}-\frac{1}{2(2+m)^{2}}-\frac{(m+1) g(l)-m \lambda}{(2+m)^{2}}-\frac{m-1}{2(2+m)^{2}}\right]\right\} \text { B.4 }\right)
\end{aligned}
$$

The numerical analysis in section 5 (Fig. 1) is based on (B.4), observing that $(l, b)$ are simultaneously given by (A.12) and (A.13), and $m$ is given by (A.10) 


\title{
CESifo Working Paper Series
}

\author{
(for full list see www.cesifo-group.de)
}

1900 Tomer Blumkin and Efraim Sadka, On the Desirability of Taxing Charitable Contributions, January 2007

1901 Frederick van der Ploeg and Reinhilde Veugelers, Higher Education Reform and the Renewed Lisbon Strategy: Role of Member States and the European Commission, January 2007

1902 John Lewis, Hitting and Hoping? Meeting the Exchange Rate and Inflation Criteria during a Period of Nominal Convergence, January 2007

1903 Torben M. Andersen, The Scandinavian Model - Prospects and Challenges, January 2007

1904 Stephane Dees, Sean Holly, M. Hashem Pesaran and L. Vanessa Smith, Long Run Macroeconomic Relations in the Global Economy, January 2007

1905 Richard Jong-A-Pin and Jakob De Haan, Political Regime Change, Economic Reform and Growth Accelerations, January 2007

1906 Sascha O. Becker and Peter H. Egger, Endogenous Product versus Process Innovation and a Firm's Propensity to Export, February 2007

1907 Theo S. Eicher, Chris Papageorgiou and Oliver Roehn, Unraveling the Fortunates of the Fortunate: An Iterative Bayesian Model Averaging (IBMA) Approach, February 2007

1908 Liliana E. Pezzin, Robert A. Pollak and Barbara S. Schone, Efficiency in Family Bargaining: Living Arrangements and Caregiving Decisions of Adult Children and Disabled Elderly Parents, February 2007

1909 Christian Keuschnigg and Soren Bo Nielsen, Self-Selection and Advice in Venture Capital Finance, February 2007

1910 Rune Jansen Hagen and Gaute Torsvik, Irreversible Investments, Dynamic Inconsistency and Policy Convergence, February 2007

1911 Eric A. Hanushek and Ludger Woessmann, The Role of School Improvement in Economic Development, February 2007

1912 Bernard M. S. van Praag, Perspectives from the Happiness Literature and the Role of New Instruments for Policy Analysis, February 2007

1913 Volker Grossmann and Thomas M. Steger, Growth, Development, and Technological Change, February 2007 
1914 Margarita Katsimi and Thomas Moutos, Human Capital and the Feldstein-Horioka Puzzle, February 2007

1915 Oliver Roehn, Theo S. Eicher and Thomas Strobel, The Ifo Industry Growth Accounting Database, February 2007

1916 Ian Babetskii, Aggregate Wage Flexibility in Selected New EU Member States, February 2007

1917 Burkhard Heer, Alfred Maussner and Paul D. McNelis, The Money-Age Distribution: Empirical Facts and Limited Monetary Models, February 2007

1918 Yin-Wong Cheung, Menzie D. Chinn and Eijii Fujii, The Overvaluation of Renminbi Undervaluation, February 2007

1919 Jim Malley, Apostolis Philippopoulos and Ulrich Woitek, To React or Not? Fiscal Policy, Volatility and Welfare in the EU-3, February 2007

1920 Mattias Polborn, Competing for Recognition through Public Good Provision, February 2007

1921 Lars P. Feld and Benno Torgler, Tax Morale after the Reunification of Germany: Results from a Quasi-Natural Experiment, February 2007

1922 Robert S. Chirinko and Huntley Schaller, Fundamentals, Misvaluation, and Investment: The Real Story, February 2007

1923 Benno Torgler and Friedrich Schneider, Shadow Economy, Tax Morale, Governance and Institutional Quality: A Panel Analysis, February 2007

1924 Adrian Pagan and M. Hashem Pesaran, On Econometric Analysis of Structural Systems with Permanent and Transitory Shocks and Exogenous Variables, February 2007

1925 Hans-Werner Sinn, The Welfare State and the Forces of Globalization, February 2007

1926 Michael Smart, Raising Taxes through Equalization, February 2007

1927 Øystein Foros, Kåre P. Hagen and Hans Jarle Kind, Price-Dependent Profit Sharing as an Escape from the Bertrand Paradox, February 2007

1928 Balázs Égert, Kirsten Lommatzsch and Amina Lahrèche-Révil, Real Exchange Rates in Small Open OECD and Transition Economies: Comparing Apples with Oranges?, February 2007

1929 Aleksander Berentsen and Cyril Monnet, Monetary Policy in a Channel System, February 2007

1930 Wolfgang Ochel, The Free Movement of Inactive Citizens in the EU - A Challenge for the European Welfare State?, February 2007 
1931 James K. Hammitt and Nicolas Treich, Statistical vs. Identified Lives in Benefit-Cost Analysis, February 2007

1932 Wilhelm Kohler, The Bazaar Effect, Unbundling of Comparative Advantage, and Migration, February 2007

1933 Karsten Staehr, Fiscal Policies and Business Cycles in an Enlarged Euro Area, February 2007

1934 Michele Bernasconi and Paola Profeta, Redistribution or Education? The Political Economy of the Social Race, March 2007

1935 Axel Dreher, Martin Gassebner and Lars-H. R. Siemers, Does Terror Threaten Human Rights? Evidence from Panel Data, March 2007

1936 Naércio Aquino Menezes Filho and Marc-Andreas Muendler, Labor Reallocation in Response to Trade Reform, March 2007

1937 Gebhard Flaig and Timo Wollmershaeuser, Does the Euro-zone Diverge? A Stress Indicator for Analyzing Trends and Cycles in Real GDP and Inflation, March 2007

1938 Michael Funke and Michael Paetz, Environmental Policy Under Model Uncertainty: A Robust Optimal Control Approach, March 2007

1939 Byeongchan Seong, Sung K. Ahn and Peter A. Zadrozny, Cointegration Analysis with Mixed-Frequency Data, March 2007

1940 Monika Bütler and Michel André Maréchal, Framing Effects in Political Decision Making: Evidence from a Natural Voting Experiment, March 2007

1941 Giacomo Corneo and Olivier Jeanne, A Theory of Tolerance, March 2007

1942 Qing Hong and Michael Smart, In Praise of Tax Havens: International Tax Planning and Foreign Direct Investment, March 2007

1943 Yin-Wong Cheung, Dickson Tam and Matthew S. Yiu, Does the Chinese Interest Rate Follow the US Interest Rate?, March 2007

1944 Panu Poutvaara and Mikael Priks, Unemployment and Gang Crime: Could Prosperity Backfire?, March 2007

1945 Burkhard Heer, On the Modeling of the Income Distribution Business Cycle Dynamics, March 2007

1946 Christoph A. Schaltegger and Lars P. Feld, Are Fiscal Adjustments less Successful in Decentralized Governments?, March 2007

1947 Giovanni Facchini, Marcelo Olarreaga, Peri Silva and Gerald Willmann, Substitutability and Protectionism: Latin America's Trade Policy and Imports from China and India, March 2007 
1948 C. Mirjam van Praag and Bernard M. S. van Praag, The Benefits of Being Economics Professor A (and not Z), March 2007

1949 Astrid Hopfensitz and Frans van Winden, Dynamic Choice, Independence and Emotions, March 2007

1950 Guglielmo Maria Caporale and Luis A. Gil-Alana, A Multivariate Long-Memory Model with Structural Breaks, March 2007

1951 Mattias Ganslandt and Keith E. Maskus, Wholesale Price Discrimination and Parallel Imports, March 2007

1952 Michela Redoano, Fiscal Interactions Among European Countries. Does the EU Matter?, March 2007

1953 Stefan C. Wolter, Rémy Hübschi and Matthias Müller, Push or Pull? An Empirical Analysis of the Demand for Individual Project Grants from the Swiss National Science Foundation, March 2007

1954 Scott Alan Carson, African-American and White Inequality in the American South: Evidence from the $19^{\text {th }}$ Century Missouri State Prison, March 2007

1955 Peter Egger, Marko Koethenbuerger and Michael Smart, Do Fiscal Transfers Alleviate Business Tax Competition? Evidence from Germany, March 2007

1956 Panu Poutvaara and Lars-H. R. Siemers, Smoking and Social Interaction, March 2007

1957 Stephan Danninger and Fred Joutz, What Explains Germany’s Rebounding Export Market Share?, March 2007

1958 Stefan Krasa and Mattias Polborn, Majority-efficiency and Competition-efficiency in a Binary Policy Model, March 2007

1959 Thiess Buettner and Georg Wamser, Intercompany Loans and Profit Shifting Evidence from Company-Level Data, March 2007

1960 Per Pettersson-Lidbom and Mikael Priks, Behavior under Social Pressure: Empty Italian Stadiums and Referee Bias, April 2007

1961 Balázs Égert and Carol S. Leonard, Dutch Disease Scare in Kazakhstan: Is it real?, April 2007

1962 Paul De Grauwe and Pablo Rovira Kaltwasser, Modeling Optimism and Pessimism in the Foreign Exchange Market, April 2007

1963 Volker Grossmann and Thomas M. Steger, Anti-Competitive Conduct, In-House R\&D, and Growth, April 2007 